\title{
Distributing responsibilities for safety from flooding
}

\author{
Neelke Doorn ${ }^{1, a}$ \\ ${ }^{1}$ Delft University of Technology, Department of Technology, Policy and Management, PO Box 5015, 2600 GA, Delft, The Netherlands
}

\begin{abstract}
In today's society, safety from flooding is no longer the sole responsibility of the central government. In recent decades, we have witnessed a governance turn in flood risk management, in which private parties as well as regional and local governmental bodies have a role to play. As a result, the question of how to distribute the responsibilities among the actors involved has become urgent. We often want distribution to be efficient and effective as well as fair. This paper presents a preliminary review of the literature on responsibility in flood risk management. The results suggests that it is important that fairness is taken into account when distributing responsibility in flood risk management. Not only does the distribution of responsibility impact how the risks and burdens themselves are distributed, allocating responsibility to individual citizens without considering the perceived fairness of the responsibility ascription may have a negative influence on the legitimacy of flood risk arrangements and lead to resistance among individual citizens to take action.
\end{abstract}

\section{Introduction}

In today's society, safety from flooding is no longer the sole responsibility of the central government. In recent decades, we have witnessed a governance turn in flood risk management, in which private parties as well as regional and local governmental bodies have a role to play. This transition has been marked by a move from controlling and defending against flooding, to the paradigm of flood risk management, which recognizes that flooding cannot and should not be prevented at all costs, but that safety should also be provided by other means [1]. In this context, government policy is achieved partly by guiding the conduct of citizens, private companies and non-governmental organizations (NGOs) [2].

As a result, the question of how to distribute the responsibilities among the actors involved has become urgent. When many different people or organizations are involved, it often becomes difficult to identify the precise person or institution responsible for performing a task. In the literature, this is often referred to as the "problem of many hands" [3-5]. Ideally, we want a distribution of responsibilities to be 'complete', in the sense that all important tasks are covered by at least one person or institution. In the governance literature, this criterion is usually interpreted in terms of effectiveness (achieving the expected results when delivering policy outcomes) and efficiency (doing it at the lowest possible cost) [6]. The philosophical literature focuses on the responsibility ascriptions being fair: under what conditions can we expect an individual to assume a particular task or responsibility [7]? This is often discussed in relation to climate change: a typical domain in which many people

${ }^{a}$ Corresponding author: N.Doorn@tudelft.nl potentially have a role to play but in which it is not evident when a responsibility ascription can be considered fair $[5,8]$.

The specific aim of the current paper is to find rationales for distributing responsibilities in flood risk management and to determine under what conditions the distribution is most likely to be both complete (i.e. effective and efficient) and fair. This question is inextricably related more generally to distributive issues, as the question of how flood risks are distributed depends on who manages the distribution, and this depends at least partly on the allocation of responsibilities [9].

\section{Method}

A systematic review methodology was applied to assess how responsibilities were distributed between public and private parties in flood risk management and whether or not there were any gaps in these distributions. Using the ISI Web of Knowledge, the largest and most comprehensive research publication database, a keyword search was carried out for English-language journal articles on responsibilities in flood risk management published between January 2000 and December 2014.

The following search strategy was used: [responsibilit*] AND [flood] AND period [2000-2014]. All subject areas in the database were included; the search was restricted to journal articles.

The academic literature was assessed in two steps. The search resulted in 172 unique publications. The abstracts were then sifted for relevance, excluding papers that were not about flood risk management. 
This produced a set of 135 papers, which was then scanned on a full-paper basis.

The results of the review will be presented in more detail elsewhere. In this paper, I focus on the rationales for distributing responsibility and how these relate to fairness and social justice. Before discussing these rationales, I would first like to clarify some terminology. Fairness and justice are notoriously difficult concepts and there is not one straightforward definition of these terms [10], let alone a widely accepted view on how these terms relate. Sometimes the terms are used interchangeably or defined in terms of one another. The political philosopher John Rawls, for example, famously developed a theory of justice as fairness [11]. Others equate fairness with equality or equity and contrast these terms this utility or total effect criteria [12]. The term distributive justice refers to the allocation of resources. In the philosophical literature, social justice is often considered an issue of domestic distributive justice, with the term global justice reserved for distributive justice on the global scale [13]. The aim of this paper is see how people distribute responsibility and to see how this affects the distribution of safety levels. I will use the term 'fair' or 'fairness' to refer to responsibilities ascriptions being considered fair or some procedure being fair. I will use the term 'social justice' to refer to the allocation of resources and the actual distribution of risks. This may lead to some inconsistencies in literal quotations, but since the paper is intended to present a review of existing literature, I gave priority to quoting people as precisely as possible.

\section{Results}

\subsection{Definition of responsibility}

Before discussing the rationales for distributing responsibility, it is good to be aware that responsibility is a notoriously difficult and ambiguous concept, with different meaning attached to it [14]. Tennekes et al. distinguish between responsibility in the sense of being the problem owner (political responsibility), being responsible for designing and carrying out measures, and being liable in the sense of having the obligation to pay [15]. Although these different types of responsibility can be ascribed to one and the same actor, this is not necessarily always the case. The focus in the current paper is on the responsibility for designing and carrying out measures. In the remainder of this text, I will refer to this responsibility as the responsibility to take measures.

\subsection{Responsibility rationales}

In this section, I discuss the different rationales that were used when distributing the responsibility to take measures. As many of the measures are quite different in nature, I first mention some general rationales that emerged from the literature, followed by a discussion of the rationales that apply specifically to measures taken before, during and after flooding.

\subsubsection{General rationales}

Under the more general header of effectiveness, some authors argue that those with a local interest in flood risk management should also be made responsible for taking measures [16]. After all, those with an interest know the context best. Especially when effective flood risk management is indeed constrained by localized knowledge, it may be effective to divide global problems of flood risk management into more tractable local problems, which allows for more localized information [17]. If the transfer of responsibility to the local level also implies a responsibility for local citizens, effectiveness requires that these citizens receive sufficient actionable information [18-22].

\subsubsection{Pre-flood: Spatial planning and training}

In terms of pre-flood measures, some authors focus on the alignment of different sectors, which would make the prevention of flood risks more effective and efficient [23]. Lack of commitment from spatial planning officials often turns out to be an obstacle to effective flood risk management [24, 25]. Aligning flood risk management with spatial planning means that either the responsibility for taking measures should be attributed to the same person or the same governmental agency responsible for spatial planning or that water and flood risk management should be integral part of land use planning. The structural integration of governmental agencies with closely related responsibilities has been recognized in the governance literature as a potentially fruitful approach to avoid fragmentation $[9,26]$.

In order to be prepared during a flood event, emergency plans should be prepared and the responsible actors should receive adequate training [27]. The Canadian emergency preparedness system, for example, involves a layered distribution of responsibility, in which initial responsibility is given to individual citizens, with municipal services responding in those situations in which the individuals cannot cope [28]. This means that the municipalities are primarily responsible for drafting an emergency plan, including its implementation. Emergency Planning Canada (EPC), a federal agency, is responsible for providing emergency preparedness training to officials from all levels of government and to private industry and for initiating public awareness programmes. From a distributive point of view, the attribution of initial responsibility to citizens, with the municipal responsibility as a back-up, can be seen as an instance of justice; more particularly, of a sufficientarian conception of justice, which holds that the trumping allocation principle of distributive justice is to secure people enough of a certain good and not to reduce inequality per se [29].

\subsubsection{During flood: emergency management}

Effective and efficient emergency management during floods requires a clear distribution of responsibility. The availability of emergency plans and procedures is the 
foundation for efficient and structured disaster management and response [27]. The empirical data on actual practice suggests that emergency plans are often empty or lacking in relevant detail, making them ineffective for guiding action [30]. Additionally, lack of communication and understanding between institutions is mentioned as an obstacle to effective emergency management during floods [28].

\subsubsection{Post-flood: compensation and recovery}

Financial compensation and recovery are the most relevant post-flood strategies. Flood insurance is one of the measures in which the distribution of responsibilities is directly related to social justice. Some authors argued that insurance by the private industry is an efficient and effective way to offer compensation for flood risks [31]. Hence, when considered from a responsibility perspective, it is more effective and efficient to allocate this responsibility to private parties than to allocate it to public authorities. Additionally, private insurance companies are said to be "more experienced in handling claims efficiently, objectively and fairly" [31]. However, more often, private flood insurance was mentioned as having a negative impact on social justice, as not all people can afford flood insurance [32, 33]. As such, it may lead to inequity. In those situations, it was recommended that the insurance premiums for those who cannot afford flood insurance should be paid through government social welfare arrangements [31, 34].

The existing systems for flood insurance are sometimes also criticized for being ineffective, as many insurance schemes do not sufficiently use incentives for risk-reducing behaviour [35]. In those situations, the distribution of responsibility for taking compensatory measures negatively impacts on the distribution of flood risk itself.

\section{Discussion}

The discussion of the distribution rationales in Section 3 points at effectiveness and efficiency as the most visible rationales. However, especially when linked to social justice, fairness considerations play an implicit role and may even contribute to the efficiency and efficacy of flood risk management.

Some articles discussed fairness in the distribution of responsibility in relation to the state's responsibility, showing show how different political theories involve a different distribution of responsibility. According to advocates of a collectivist welfare state, responsibility cannot be attributed solely to private parties as this may lead to inequality. In this view, flood risk management should preferably include public adaptation strategies to deal with distributional effects [36]. As such, the distribution of responsibility between public and private actors is clearly a political question, which can partly explain the divergence of strategies within Europe but also some changes over time [15, 36, 37].

In line with this more political discussion, an important consideration mentioned in a significant number of publications was legitimacy. Some authors argued that private actors must accept the responsibilities assigned to them for a flood risk arrangement to be viewed as legitimate [32]. This lack of acceptance was linked by some authors to a lack of reliable and actionable information [18-22] or a lack of awareness $[38,39]$, but empirical studies on perceived responsibility show a more nuanced picture.

Empirical studies of people's perceived responsibility for damage mitigation and flood preparedness showed that people who acknowledge their own role in flood risk management are open to flood risk communication, but that those who do not accept the personal responsibility of citizens are not open to this type of communication [40]. Similar findings emerged from a qualitative study on risk awareness campaigns [41] and 'policy transitions' in flood risk management [2].

Before focusing on risk communication and awareness campaigns, it may therefore be good to take a closer look at when and under what conditions people accept individual responsibility. By examining articles from the perspective of fairness, three important themes emerged.

Causality: The first important condition for responsibility is the causal connection between an action and an outcome. Some empirical studies confirm that citizens do indeed relate the responsibility to take preventive measures to the presence of a causal connection. For example, a study on flood preparedness in Vietnam suggests that those who see management failures as the cause of flooding, are less likely to accept a responsibility for citizens to take flood mitigation measures [42]. In the more general context of water management, a survey among Australian citizens suggests that most citizens accept more responsibility for addressing environmental problems if there is also a causal link between these problems and individual behaviour [43].

In a more indirect way, it has been argued that if one freely chooses to live in a flood-prone area, this can be seen as a form of risk acceptance and one thereby becomes the 'problem owner'. However, vulnerable people, such as the elderly or people with lower incomes, are often unable to move away [44]. In those situations, it is generally considered unfair to say that those people have causally contributed to their own situation of being at risk of flooding.

Capacity: In the philosophical literature on responsibility, capacity is often mentioned as one of the conditions for responsibility. If people do not have the relevant knowledge on which to base their actions, lack relevant resources or do not have control over their actions, they cannot be held responsible.

Although most papers discussed capacity under the heading of effectiveness - i.e. flood risk management measures being ineffective due to people lacking the capacity or resources to assume this responsibility - some papers explicitly framed it as an issue of equity or social justice $[45,46]$. A transfer of responsibility to local actors runs the risk of increased inequality if vulnerable groups 
lack the social and cultural capital and capacity, as well as economic power or national strategic interests, to profit equally from this shift of responsibility [46]. Based on the African context, one paper argued for more empowering initiatives that allow "people who face hazards to manage their own environments more responsibly and equitably over the long term" [47].

Power and agency: A third theme that emerged from the review was the issue of power and perceived agency that individuals experience in flood risk management [2]. As one study mentioned, "people need to believe that they can take action, and that their efforts are worthwhile" [41]. Many initiatives to involve stakeholders are primarily aimed at 'educating' the public and less on 'genuine engagement' [21], in which the objectives of flood risk management are also open to discussion [48].

Interestingly, although the discussion of objectives seems to be primarily an issue of democracy ('having a voice'), the discussion of objectives was also seen as instrumental to effectiveness as it would improve interorganizational coordination [49]. Analogously, one paper argued that "in order to be effective, adaptation options have to work technically (...), but also be feasible (...), and acceptable to those implementing them or affected by them" [50].

\section{Concluding remarks}

This preliminary review suggests that fairness is an important consideration to take into account when distributing responsibility in flood risk management. Fairness is relevant in at least the following three ways.

First, the distribution of responsibility has an impact on how the risks and burdens are distributed, as most clearly illustrated in the responsibility to take compensatory measures. If flood insurance becomes primarily a matter of individuals taking out private insurance, this may increase inequality between those who can and those who cannot afford flood insurance. As such, fairness (in the allocation of responsibilities) has an impact on the distribution of risk levels (i.e., social justice).

Second, while admittedly the distribution of responsibility between the state and individual citizens depends partly on one's view of the state, even in a minimal state view, the state has a responsibility to provide basic protection against flooding. Individuals can only be given a role if they have the capacity and resources to respond adequately. It is the state's responsibility to ensure that these conditions are indeed met before it can transfer responsibility to individual citizens. Additionally, from a democratic point of view, individual citizens should be given a voice when deciding about the objectives of flood risk management.

Third, even if one does not take into account the fairness of the responsibility ascription for ethical reasons, fairness may still be instrumental to effective flood risk management. It was shown that the extent to which responsibility is actually taken up depends partly on whether people consider it fair that they are given a responsibility.

These preliminary results suggest that the distribution of responsibility in flood risk management is more than an issue of efficiency and effectiveness. When engaging citizens in flood risk management, fairness and social justice may be equally important considerations.

\section{Acknowledgments}

This research is supported by the Netherlands Organisation for Scientific Research (NWO) under Grant 016-144-071.

\section{References}

1. Johnson, C.L. and S.J. Priest, Flood risk management in England: A changing landscape of risk responsibility? International Journal of Water Resources Development, 2008. 24(4): pp. 513-525.

2. Butler, C. and N. Pidgeon, From 'flood defence' to 'flood risk management': exploring governance, responsibility, and blame. Environment and Planning C-Government and Policy, 2011. 29(3): pp. 533-547.

3. Thompson, D.F., Moral responsibility and public officials. American Political Science Review, 1980. 74: pp. 905-916.

4. Doorn, N. and I.R. Van de Poel, Editors' overview: Moral responsibility in technology and engineering. Science and Engineering Ethics, 2012. 18(1): pp. 111.

5. Van de Poel, I.R., et al., The problem of many hands: Climate change as an example. Science and Engineering Ethics, 2012. 18(1): pp. 49-67.

6. OECD, Water Governance in the Netherlands: Fit for the Future? OECD Studies on Water OECD. 2014, Paris: OECD Publishing.

7. Doorn, N., Responsibility ascriptions in technology development and engineering: Three perspectives. Science and Engineering Ethics, 2012. 18(1): pp. 69-90.

8. Peeters, W., et al., Climate Change and Individual Responsibillity: Agency, Moral Disengagement and the Motivational Gap. 2015, London: Palgrave Macmillan.

9. Mostert, E., Who should do what in environmental management? Twelve principles for allocating responsibility. Environmental Science and Policy, 2015. 45: pp. 123-131.

10. Doorn, N., The blind spot in risk ethics: Managing natural hazards. Risk Analysis, 2015. 35(3): pp. 354-360.

11. Rawls, J., A Theory of Justice. Revised Edition ed. 1999[1971], Cambridge, MA: The Belknap Press of Harvard University Press.

12. Jongejan, R.B., S.N. Jonkman, and J.K. Vrijling, An overview and discussion of methods for risk evaluation, in Risk, Reliability and Societal Safety, Vols 1-3 - Vol 1: Specialisation Topics; Vol 2: 
Thematic Topics; Vol 3: Applications Topics, T. Aven and J.E. Vinnem, Editors. 2007. p. 1391-1398.

13. Miller, D., Justice for Earthlings. Essays in Political Philosophy. 2013, Cambridge: Cambridge University Press.

14. Miller, D., Distributing responsibilities. The Journal of Political Philosophy, 2001. 9(4): pp. 453-471.

15. Tennekes, J., et al., Out of the Comfort Zone: Institutional Context and the Scope for Legitimate Climate Adaptation Policy. Journal of Environmental Policy \& Planning, 2014. 16(2): pp. 241-259.

16. Barron, S., et al., A Climate Change Adaptation Planning Process for Low-Lying, Communities Vulnerable to Sea Level Rise. Sustainability, 2012. 4(9): pp. 2176-2208.

17. Lynch, A.H. and R.D. Brunner, Context and climate change: An integrated assessment for Barrow, Alaska. Climatic Change, 2007. 82(1-2): pp. 93-111.

18. Nye, M., S. Tapsell, and C. Twigger-Ross, New social directions in UK flood risk management: moving towards flood risk citizenship? Journal of Flood Risk Management, 2011. 4(4): pp. 288-297.

19. Olsson, E.K., Crisis Communication in Public Organisations: Dimensions of Crisis Communication Revisited. Journal of Contingencies and Crisis Management, 2014. 22(2): pp. 113-125.

20. Stevens, M.R. and S. Hanschka, Multilevel Governance of Flood Hazards: Municipal Flood Bylaws in British Columbia, Canada. Natural Hazards Review, 2014. 15(1): pp. 74-87.

21. Harvatt, J., J. Petts, and J. Chilvers, Understanding householder responses to natural hazards: flooding and sea-level rise comparisons. Journal of Risk Research, 2011. 14(1): pp. 63-83.

22. Keogh, D.U., et al., Resilience, vulnerability and adaptive capacity of an inland rural town prone to flooding: a climate change adaptation case study of Charleville, Queensland, Australia. Natural Hazards, 2011. 59(2): pp. 699-723.

23. Lawrence, J., D. Quade, and J. Becker, Integrating the effects of flood experience on risk perception with responses to changing climate risk. Natural Hazards, 2014. 74(3): pp. 1773-1794.

24. Neuvel, J.M.M. and A. Van den Brink, Flood risk management in Dutch local spatial planning practices. Journal of Environmental Planning and Management, 2009. 52(7): pp. 865-880.

25. Niebling, W., et al., Challenge and response in the Mississippi River Basin. Water Policy, 2014. 16: pp. 87-116.

26. Doorn, N., Allocating responsibility for environmental risks: A comparative analysis of examples from water governance. Integrated Environmental Assessment and Management, 2016.

27. Fillmore, E.P., et al., After the Waters Receded: A Qualitative Study of University Official's Disaster Experiences During the Great Iowa Flood of 2008. Journal of Community Health, 2011. 36(2): pp. 307315.

28. Haque, C.E., Risk assessment, emergency preparedness and response to hazards: The case of the 1997 Red River Valley flood, Canada. Natural Hazards, 2000. 21(2-3): pp. 225-245.

29. Crisp, R., Equality, Priority, and Compassion. Ethics, 2003. 113(4): pp. 745-763.

30. Lumbroso, D., K. Stone, and F. Vinet, An assessment of flood emergency plans in England and Wales, France and the Netherlands. Natural Hazards, 2011. 58(1): pp. 341-363.

31. Crichton, D., UK and global insurance responses to flood hazard. Water International, 2002. 27(1): pp. 119-131.

32. Mees, H.L.P., P.P.J. Driessen, and H.A.C. Runhaar, Legitimate adaptive flood risk governance beyond the dikes: the cases of Hamburg, Helsinki and Rotterdam. Regional Environmental Change, 2014. 14(2): pp. 671-682.

33. Dahlstrom, K., J. Skea, and W.R. Stahel, Innovation, insurability and sustainable development: Sharing risk management between insurers and the state. Geneva Papers on Risk and Insurance-Issues and Practice, 2003. 28(3): pp. 394412.

34. Blanchard-Boehm, R.D., K.A. Berry, and P.S. Showalter, Should flood insurance be mandatory? Insights in the wake of the 1997 New Year's Day flood in Reno-Sparks, Nevada. Applied Geography, 2001. 21(3): pp. 199-221.

35. Keskitalo, E.C.H., G. Vulturius, and P. Scholten, Adaptation to climate change in the insurance sector: examples from the UK, Germany and the Netherlands. Natural Hazards, 2014. 71(1): pp. 315 334.

36. Keessen, A.M., et al., The Concept of Resilience from a Normative Perspective: Examples from Dutch Adaptation Strategies. Ecology and Society, 2013. 18(2): pp. 12.

37. Adger, W.N., et al., Changing social contracts in climate-change adaptation. Nature Climate Change, 2013. 3(4): pp. 330-333.

38. Tas, M., et al., Flood disaster vulnerability in informal settlements in Bursa, Turkey. Environment and Urbanization, 2013. 25(2): pp. 443-463.

39. Kreibich, H., Do perceptions of climate change influence precautionary measures? International Journal of Climate Change Strategies and Management, 2011. 3(2): pp. 189-199.

40. Terpstra, T. and J.M. Gutteling, Households' perceived responsibilities in flood risk management in the Netherlands. International Journal of Water Resources Development, 2008. 24(4): pp. 555-565.

41. Soane, E., et al., Flood perception and mitigation: the role of severity, agency, and experience in the purchase of flood protection, and the communication of flood information. Environment and Planning A, 2010. 42(12): pp. 3023-3038.

42. Schad, I., et al., Why do people not learn from flood disasters? Evidence from Vietnam's northwestern mountains. Natural Hazards, 2012. 62(2): pp. 221241.

43. Burton, M., S. Marsh, and J. Patterson, Community attitudes towards water management in the Moore 
Catchment, Western Australia. Agricultural Systems, 2007. 92(1-3): pp. 157-178.

44. Bichard, E. and A. Kazmierczak, Are homeowners willing to adapt to and mitigate the effects of climate change? Climatic Change, 2012. 112(3-4): pp. 633-654.

45. Mullins, A. and R. Soetanto, Ethnic differences in perceptions of social responsibility Informing risk communication strategies for enhancing community resilience to flooding. Disaster Prevention and Management, 2013. 22(2): pp. 119-131.

46. Thaler, T. and S. Priest, Partnership funding in flood risk management: new localism debate and policy in England. Area, 2014. 46(4): pp. 418-425.

47. Douglas, I., et al., Unjust waters: climate change, flooding and the urban poor in Africa. Environment and Urbanization, 2008. 20(1): pp. 187-205.

48. Karanikola, P., et al., Facing and managing natural disasters in the Sporades islands, Greece. Natural Hazards and Earth System Sciences, 2014. 14(4): pp. 995-1005.

49. Greiving, S., et al., Linking the actors and policies throughout the disaster management cycle by "Agreement on Objectives" - a new output-oriented management approach. Natural Hazards and Earth System Sciences, 2012. 12(4): pp. 1085-1107.

50. Williams, K., et al., Retrofitting England's suburbs to adapt to climate change. Building Research and Information, 2013. 41(5): pp. 517-531. 